REVIEWARTICLE

\section{Contribution of Extracellular Vesicles to Cancer Initiation through Cellular Senescence during Aging}

\author{
Naoomi Tominaga ${ }^{1,2,3^{*}}$ \\ ${ }^{1}$ Division of Molecular Therapy, Institute of Medical Science, University of Tokyo, Tokyo, Japan \\ ${ }^{2}$ Department of Biology, Massachusetts Institute of Technology, Cambridge, USA \\ ${ }^{3}$ JSPS Oversea Research Fellow
}

\begin{abstract}
Extracellular vesicles (EVs) are microvesicles secreted from cells with critical roles in cell-tocell communication. Over the past three decades, EV biology has been characterized by many researchers. Importantly, EVs promote many steps of cancer progression, including cancer cell proliferation, metastasis, formation of pre-metastasis niches, and immunomodulation. Recently, it was shown senescent cells secrete many types of molecules, including EVs, which is termed senescence-associated secretory phenotype. The molecules secreted from cells with the senescence-associated secretory phenotype are related to inflammation, cell proliferation, and cancer initiation. It has also been shown that cellular senescence contributes to cancer progression through EVs. In this present review, the contribution of EVs to cancer biology through senescent cells and aging is summarized and discussed.
\end{abstract}

\section{Keywords}

Extracellular vesicles (EVs), exosome, cell-cell communication senescence, cancer, carcinogenesis

\section{Introduction}

Citation: Tominaga, N. Contribution of Extracellular Vesicles to Cancer Initiation through Cellular Senescence during Aging. Cancer Studies. 2018; 1(1):6.

Received: October 31, 2017 Accepted: January 31, 2018 Published: February 20, 2018

Copyright: @ $\odot 2018$ Tominaga N. This is an open access article distributed under the terms of the Creative Commons Attribution License, which permits unrestricted use, distribution, and reproduction in any medium, provided the original author and source are credited.

\section{Corresponding author:}

Naoomi Tominaga, Department of Biology, Massachusetts Institute of Technology, 77 Massachusetts Avenue, 68-280, Cambridge, MA 02139, USA. E-mail: ntominag@mit.edu

\section{Cellular senescence and the senescence-associated secretory phenotype}

Cellular senescence is a cellular state characterized by arrest of cell growth, enlarged morphology, and changes in chromatin and the secretome.$^{1,2} \mathrm{It}$ was originally advocated by Dr. Hayflick in 1961 and is well known as the "Hayflick limit." ${ }^{3,4}$ Cellular senescence can be categorized by external and internal changes. Damage to genomic and telomeric DNA can trigger the DNA damage response..$^{5-7}$ Senescent cells accumulate mutations in their genome ${ }^{8}$ that trigger this DNA damage response, thus activating ataxia telangiectasia mutated (ATM) and $\mathrm{p} 53$, which initiate and maintain cell growth arrest. ${ }^{9,10}$ Expression of p16INK4a, which has regulatory roles with CDK4 and p53 in cell cycle G1 progression, and Wnt family member 16 (WNT16B) is also characteristic of senescent cells ${ }^{11}$ and contributes to the maintenance of homeostasis in organisms. These cellular states have been considered tumor suppression mechanisms. ${ }^{5,12,13}$ However, this emerging theory appears paradoxical. ${ }^{1,14}$ Senescent cells secrete many factors into the extracellular environment, which is known as a senescenceassociated secretory phenotype (SASP). ${ }^{15,16}$ This SASP includes secretion of many factors, including amphiregulin (AREG), granulocyte-macrophage colony-stimulating factor (GMCSF), C-X-C chemokines (CXCLs), interleukin-6 (IL-6), interleukin-8 (IL-8), matrix metalloproteinases (MMPs), monocyte chemoattractant proteins (MCPs), plasminogen activator inhibitor-1 (PAI-1), vascular endothelial growth factor (VEGF), and extracellular vesicles (EVs), that control cell growth, motility, differentiation, and inflammation. ${ }^{17,18}$ In humans, there are tissue-resident senescent cells that contribute to aging and age-related diseases through the SASP. ${ }^{3,19}$ These SASP-associated factors facilitate tumor cell invasion 
and metastasis by inducing epithelial-to-mesenchymal transition. ${ }^{14,15}$ Furthermore, it was shown in 2013 that the SASP is a key promoter of obesity-associated hepatocellular carcinoma development. Specifically, increased deoxycholic acid levels from gut microbiota in obese organisms induce the secretion of various inflammatory and tumor-promoting factors from hepatic stellate cells with the SASP. Hepatocellular carcinomas are facilitated by exposure to these factors. ${ }^{20}$ Moreover, SASP factors promote cancer cell invasion, metastasis, and cellular epithelial-to-mesenchymal transition. ${ }^{1,15,21}$ Therefore, SASPassociated factors influence cancer initiation and malignancy. However, this does not contradict a possible role for EVs produced by senescent cells in promoting the development of cancer.

\section{EVs are secreted by numerous cell types}

EVs were first reported in 1983 by Jonstone et al. ${ }^{22}$ Over the past three decades, EVs, such as exosomes, macrovesicles, and ectosomes, have emerged as novel biological mediators of cell-to-cell communication. ${ }^{23,24}$ EVs contain several types of molecules, including lipids, proteins, messenger RNAs (mRNAs), and microRNAs (miRNAs). ${ }^{25}$ Moreover, EVs are secreted from many types of normal and pathological cells. ${ }^{25}$ There remains confusion regarding the terminology for these secreted vesicles and distinguishing characteristics between exosomes, macrovesicles, ectosomes, etc., partially because it is difficult to distinguish between vesicle types following secretion using the currently available purification methods. In this review, to avoid such confusion, the term "extracellular vesicles" is used. ${ }^{24,26}$

\section{The role of EVs in cancer biology}

Recently, evidence of the importance of EVs in cancer biology has accumulated. ${ }^{24}$ After the transfer of miRNAs and mRNAs to other cells by EVs were found in $2007,{ }^{27}$ it became clear that EVs affect characteristics associated with cancer malignancy, including cancer cell proliferation, ${ }^{28-30}$ immunomodulation, ${ }^{31-34}$ angiogenesis, ${ }^{29,30,35,36}$ formation of pre-metastasis niches, ${ }^{37}$ and metastasis. ${ }^{38,39}$ Furthermore, it is possible non-invasive tests could be used to diagnose cancers based on detection of cancer-derived EVs. ${ }^{40,41} \mathrm{EVs}$ also have the potential to be applied in drug delivery systems ${ }^{42,43}$ and in cancer therapy. ${ }^{44,45}$. As previously mentioned, the importance of EVs in cancer malignancy, progression, diagnosis, and treatment has been demonstrated. However, the role of senescent cell-derived EVs in cancer initiation remains to be elucidated.

\section{Aging-associated alterations in EVs contents}

Many studies have shown EVs contents and secretion levels have an important relationship with aging. ${ }^{46} \mathrm{EV}$ protein, ${ }^{47-50} \mathrm{mRNA},{ }^{51}$ lipid, ${ }^{50}$ and miRNA content ${ }^{52-57}$ typically increase in aging or senescent cells, while levels of some other molecules decrease (Table 1). In addition, many studies have shown the amount of EVs change with age..$^{21,47,50,53,56-59}$ In the case of EVencapsulated miRNA, miRNA profiles vary with age and these miRNAs can be transferred to other cells. EV secretion from endothelial colony-forming cells was recently shown to be promoted by sirtuin-1 deficiency ${ }^{60}$ and could possibly explain increases in EV secretion in senescent cells. By contrast, the number of EVs circulating in humans does not increase with age, which is a reflection of the inflammation status and frailty. ${ }^{61}$ Furthermore, it has been reported EV concentrations decrease with age, where EVs in human serum are ingested by monocytes and $\mathrm{B}$ cells. ${ }^{62}$ However, these do not exclude the possibility there is an alteration in EV content. As mentioned above, EV content changes with age in humans. The change in EV number remains controversial, but is probably related to other changes in the EV profile that occur with aging. 
Table 1. Contents and function of EVs from senescence cells or blood samples obtained from age

\begin{tabular}{|c|c|c|c|c|c|}
\hline Type & $\begin{array}{l}\text { The alteration of } \\
\text { component }\end{array}$ & Function & $\begin{array}{l}\text { The alteration of } \\
\text { EVs amount }\end{array}$ & Origin of EVs & References \\
\hline \multirow[t]{4}{*}{ Protein } & $\begin{array}{l}\text { TSN1, PODXL, IDHC, } \\
\text { PPAP, ACBP, and } \\
\text { ANXA5 }\end{array}$ & - & increase & Urine from elderly individuals & 47 \\
\hline & Galectin-3 & $\begin{array}{l}\text { inhibition of osteogenic } \\
\text { differentiation }\end{array}$ & decrease & Plasma in elderly individuals & 48 \\
\hline & EphA2 & $\begin{array}{l}\text { promotion of cancer cell } \\
\text { proliferation }\end{array}$ & increase & $\begin{array}{l}\text { senescent RPE1 pigmented } \\
\text { epithelium cells }\end{array}$ & 49 \\
\hline & $\begin{array}{l}\alpha-S y n u c l e i n, \text { amyloid- } \beta \\
(A \beta) \text { precursor protein }\end{array}$ & re & increase & $\begin{array}{l}\text { Platelet from healthy } \\
\text { individuals }\end{array}$ & 50 \\
\hline mRNA & IL-6, IL-12 & - & increase & $\begin{array}{l}\text { macrophage of elderly } \\
\text { individuals }\end{array}$ & 51 \\
\hline Lipid & ApoE, ApoJ & - & increase & $\begin{array}{l}\text { Platelet from healthy } \\
\text { individuals }\end{array}$ & 50 \\
\hline \multirow[t]{7}{*}{ miRNA } & miR-31 & $\begin{array}{l}\text { inhibition of osteogenic } \\
\text { differentiation of mesenchymal } \\
\text { stem cells }\end{array}$ & increase & senescent endothelial cells & 52 \\
\hline & $\operatorname{miR}-185-5 p$ & $\begin{array}{l}\text { cell proliferation and osteogenic } \\
\text { differentiation inhibition }\end{array}$ & increase & $\begin{array}{l}\text { aged bone marrow stromal } \\
\text { cells (BMSCs) from elderly } \\
\text { mice }\end{array}$ & 53 \\
\hline & miR-133b-3p, miR-294 & $\begin{array}{l}\text { inhibition of TGF- } \beta 1 \text {-mediated } \\
\text { epithelial-mesenchymal transition } \\
\text { (EMT) in HK2 cells }\end{array}$ & decrease & $\begin{array}{l}\text { bone marrow mesenchymal } \\
\text { stem cell in older rats }\end{array}$ & 54 \\
\hline & miR-24-3p & a novel aging biomarker & increase & healthy old individuals & 55 \\
\hline & $\begin{array}{l}\text { miR-144-3p, miR-486- } \\
5 p, \quad \text { miR-142-5p, } \\
\text { miR-451a, miR- } \\
\text { 25-3p, miR-145-5p, let- } \\
7 f-5 p\end{array}$ & 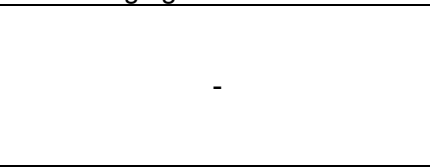 & increase & senescent platelet & 56 \\
\hline & $\begin{array}{l}\text { miR-126-5p, miR-148a- } \\
\text { 3p, miR28-3p, miR27b- } \\
\text { 3p, miR-10a-5p, } \\
\text { miR-215-5p }\end{array}$ & - & increase & $\begin{array}{l}\text { postmenopausal no } \\
\text { estrogenic hormone } \\
\text { replacement therapy (HRT) } \\
\text { group vs premenopausal } \\
\text { group }\end{array}$ & 57 \\
\hline & $\begin{array}{l}\text { miR142-5p, miR-484, } \\
\text { miR10b, miR-144-5p }\end{array}$ & - & decrease & $\begin{array}{l}\text { postmenopausal no } \\
\text { estrogenic hormone } \\
\text { replacement therapy (HRT) } \\
\text { group vs premenopausal } \\
\text { group }\end{array}$ & 57 \\
\hline
\end{tabular}

Some studies have detected alterations in EV content by comparing healthy young and aged individuals. Levels of six proteins, TSN1, PODXL, IDHC, PPAP, ACBP, and ANXA5, in EVs isolated from urine were distinct between people aged 25-50 and 50-70 years. ${ }^{47}$ The authors mentioned a possibility that these proteins has been implicated in cancer and cancer prognosis. In addition, the EV lipidomic profile also differed in senescent platelets. ${ }^{50} \mathrm{An}$ aging biomarker, miR-24-3p, was identified by assessing the miRNAs in EVs isolated from saliva from young healthy (median age, 21.0 years) and older volunteers (median age, 66.0 years).$^{55}$ Recent studies have shown levels of miR-96/-182/-183, i.e., the miR-183 cluster, increase with age in EVs from the bone marrow interstitial fluid of young (3-4 months) and aged (24-28 months) mice. ${ }^{53}$

Studies have shown EV components differ between diseased and healthy individuals. ${ }^{63-65}$ Ten miRNAs from serum EVs were found to have age-related differences by comparing postmenopausal individuals not undergoing estrogenic hormone replacement therapy to premenopausal individuals. ${ }^{57}$ In 2009, it was reported EVs may be potential markers of agerelated macular degeneration pathogenesis. ${ }^{66,67}$ Therefore, it is clear EVs contents change with age.

\section{EV functions in aging individuals and senescent cells}

Studies on the SASP and EVs have raised questions concerning the contribution of EVs to cancer initiation due to alterations in EV profiles during aging. In recent years, it has been found cell senescence mechanisms promote carcinogenesis, which appears to be a "doubleedged sword." ${ }^{20,46}$ As mentioned above, one aspect of the SASP is its anti-cancer function. For example, EV secretion maintains homeostasis by discarding accumulated DNA. ${ }^{58}$ An inhibition of EV secretion will be induced the innate immune response, senescence-like cell- 
cycle arrest, and/or apoptosis in normal human cells. However, other aspects of the SASP play a role in cancer initiation and disease promotion. It was reported senescent platelets secrete EVs containing miRNAs associated with atherosclerosis, inflammation, and neurodegeneration. ${ }^{56}$ The authors investigated EVs from concentrated human donor platelets, which were stored for 0 to 5 days. Upregulation of miR-144-3p, miR-486-5p, miR$142-5 p$, miR-451a, miR-25-3p, miR-145-5p, and let-7f-5p, which contribute to certain agerelated diseases, was observed in EVs from senescent platelets. Recent studies have shown EV-derived miR-183-5p from aged bone marrow reduced stem cell proliferation and inhibited osteogenic differentiation, contributing to stem cell senescence in vitro. ${ }^{53}$

In addition, EVs in fetal bovine and human serum contribute to cell growth and promote survival. ${ }^{68}$ Many cell lines, including human U87 glioblastoma, human embryonic kidney 293T, HeLa cervical cancer, human SH-SY5Y neuroblastoma, and mouse N2a neuroblastoma cells, grow in EV-depleted serum. However, this growth is enhanced upon the addition of EVs to the serum. The authors discussed the possibility circulating EVs support cell growth and survival in vivo. Endothelial cell EV-derived miR-214 also promote migration and angiogenesis of neighbor cells by reducing cell senescence through repression of ATM by miR-214 expression in vitro and in vivo. ${ }^{69}$ The authors suggested that the senescent cells with reduced miR-214 levels rescue from entering senescence by incorporating miR-214 from neighboring miR-214-producing cells via the exosomal shuttle. As mentioned previously, it is possibility that these entering senescent cell have been accumulated the mutation in the genome. Importantly, the EPH receptor A2 (EphA2), which is found in EVs, promotes cancer cell proliferation ${ }^{49}$ and EVs from senescent cells are enriched in EphA2. These EphA2containing EVs bind to ephrin-A1 on the surface of cancer cells and, thus, promote cancer cell proliferation through EphA2/ephrin-A1 reverse signaling. The authors suggested EVs from senescent cells have pro-tumorigenic functions. Furthermore, EVs from senescent cells contain certain disease-related components, such as those associated with atherosclerosis, inflammation, and neurodegeneration. Moreover, EV secretion is upregulated with aging. Inflammation has a well-known relationship with cancer initiation. ${ }^{17}$ Importantly, the inflammation-associated EV content increases in the bloodstream with aging. ${ }^{49,51,70}$ One possible explanation is EVs promote cancer initiation through such changes in their profile with age, such as EV-associated induction of inflammation and the uptake of EVs containing disease-related components. However, it is a juvenile field and there is not sufficient evidence for cancer initiation by EVs secreted from senescent cells.

\section{Prospect}

Through the extensive efforts of many researchers, different aspects of cancer malignancy have been associated with cell-derived EVs. Recently, it was revealed senescent cells secrete EVs with a different profile than EVs from non-senescent cells. Furthermore, EVs from senescent cells are associated with age-related diseases, such as inflammation, atherosclerosis, and neurodegeneration, and promotion of cancer cell proliferation. Although it is not clear the contribution of EVs to the cancer initiation, but the traditional hypothesis is inflammation and immune responses contribute to cancer initiation. ${ }^{71-74}$ Moreover, EVs from senescent cells promote cancer progression by activating cell signaling. We can speculate EV secretion from senescent cells contributes to cancer initiation through aging. However, this area of research has yet to be fully explored. Further studies are needed to determine the effect of age-related alterations in circulating EVs on cancer initiation.

\section{Author Disclosure}

The author has no conflicts of interest.

\section{Acknowledgments}

This study was partly supported by the Foundation for JSPS Oversea Research Fellowship, Japan. I thank Dr. Kana Tominaga for to provide helpful discussion. 


\section{References}

1. Rodier F \& Campisi J. Four faces of cellular senescence. J. Cell Biol. 2011; 192: 547-556.

2. Bavik C, Coleman I, Dean JP, et al. The gene expression program of prostate fibroblast senescence modulates neoplastic epithelial cell proliferation through paracrine mechanisms. Cancer Res.2006; 66: 794-802.

3. Hayflick L \& Moorhead PS. The serial cultivation of human diploid cell strains. Exp Cell Res. 1961; 25: $585-621$.

4. Hayflick L. The limited in vitro lifetime of human diploid cell strains. Exp Cell Res. 1965; 37: 614-636.

5. d'Adda di Fagagna F, Reaper PM, Clay-Farrace L, et al. A DNA damage checkpoint response in telomere-initiated senescence. Nature. 2003; 426: 194-198.

6. Herbig U, Jobling WA, Chen BPC, Chen DJ \& Sedivy JM. Telomere shortening triggers senescence of human cells through a pathway involving ATM, p53, and p21CIP1, but not p16INK4a. Mol Cell. 2004; 14: $501-513$

7. Piast M, Kustrzeba-Wójcicka I, Matusiewicz M. \& Banaś T. Molecular evolution of enolase. Acta Biochim Pol. 2005; 52: 507-513.

8. Nakamura AJ. Chiang YJ, Hathcock KS, et al. Both telomeric and non-telomeric DNA damage are determinants of mammalian cellular senescence. Epigenetics Chromatin 2008; 1: 6.

9. Ogryzko VV, Hirai TH, Russanova VR, Barbie DA \& Howard BH. Human fibroblast commitment to a senescence-like state in response to histone deacetylase inhibitors is cell cycle dependent. Mol Cell Biol. 1996; 16: 5210-5218.

10. Bakkenist CJ \& Kastan MB. DNA damage activates ATM through intermolecular autophosphorylation and dimer dissociation. Nature. 2003; 421:499-506.

11. Binet R, Ythier D, Robles Al, et al. WNT16B is a new marker of cellular senescence that regulates $p 53$ activity and the phosphoinositide 3-kinase/AKT pathway. Cancer Res.2009; 69: 9183-9191.

12. Hara E, Tsurui H, Shinozaki A, Nakada S \& Oda K. Cooperative effect of antisense-Rb and antisensep53 oligomers on the extension of life span in human diploid fibroblasts, TIG-1. Biochem Biophys Res Commun. 1991; 179: 528-534.

13. Shay JW, Pereira-Smith OM \& Wright WE. A role for both RB and p53 in the regulation of human cellular senescence. Exp Cell Res. 1991; 196: 33-39.

14. Lecot P, Alimirah F, Desprez P-Y, Campisi J \& Wiley C. Context-dependent effects of cellular senescence in cancer development. Br J Cancer. 2016; 114: 1180-1184.

15. Coppé JP, Patil CK, Rodier F, et al. Senescence-Associated Secretory Phenotypes Reveal CellNonautonomous Functions of Oncogenic RAS and the p53 Tumor Suppressor. PLoS Biol. 2008; 6: e301.

16. Kuilman T \& Peeper DS. Senescence-messaging secretome: SMS-ing cellular stress. Nat Rev Cancer. 2009;9: 81-94.

17. Elinav E, Nowarski R, Thaiss CA, et al. Inflammation-induced cancer: crosstalk between tumours, immune cells and microorganisms. Nat. Rev. Cancer. 2013; 13: 759-771.

18. Re RN \& Cook JL. Senescence, apoptosis, and stem cell biology: the rationale for an expanded view of intracrine action. AJP Hear Circ Physiol. 2009;297: H893-H901.

19. Dimri GP, Lee X, Basile G, et al. A biomarker that identifies senescent human cells in culture and in aging skin in vivo. Proc Natl Acad Sci. 1995;92: 9363-9367.

20. Yoshimoto S, Loo TM, Atarashi K, et al. Obesity-induced gut microbial metabolite promotes liver cancer through senescence secretome. Nature. 2013;499: 97-101.

21. Wang Z, Deng Z, Dahmane N, et al. Telomeric repeat-containing RNA (TERRA) constitutes a nucleoprotein component of extracellular inflammatory exosomes. Proc Natl Acad Sci. 2015;112: E6293-E6300.

22. Pan BT \& Johnstone RM. Fate of the transferrin receptor during maturation of sheep reticulocytes in vitro: selective externalization of the receptor. Cell. 1983;33: 967-978.

23. Raposo G \& Stoorvogel W. Extracellular vesicles: Exosomes, microvesicles, and friends. J Cell Biol. 2013;200: 373-383. 
24. Tominaga N, Katsuda T \& Ochiya T. Micromanaging of tumor metastasis by extracellular vesicles. Semin. Cell Dev Biol. 2015;40: 52-59.

25. Mathivanan S, Ji H \& Simpson RJ. Exosomes: Extracellular organelles important in intercellular communication. J Proteomics 2010;73: 1907-1920.

26. Gould SJ \& Raposo G. As we wait: coping with an imperfect nomenclature for extracellular vesicles. J Extracell. vesicles 2013;2: 3-5.

27. Valadi $\mathrm{H}$, Ekström $\mathrm{K}$, Bossios $\mathrm{A}$, et al. Exosome-mediated transfer of mRNAs and microRNAs is a novel mechanism of genetic exchange between cells. Nat Cell Biol. 2007;9: 654-659.

29. Chairoungdua A, Smith DL, Pochard P, Hull M \& Caplan MJ. Exosome release of $\beta$-catenin: a novel mechanism that antagonizes Wnt signaling. J Cell Biol. 2010;190: 1079-1091.

30. Al-Nedawi K, Meehan B, Micallef J, et al. Intercellular transfer of the oncogenic receptor EGFRvIII by microvesicles derived from tumour cells. Nat Cell Biol. 2008;10: 619-624.

31. Skog J, Wurdinger T, Rin S, et al. Glioblastoma microvesicles transport RNA and proteins that promote tumour growth and provide diagnostic biomarkers. Nat Cell Biol. 2008;10: 1470-1476.

32. Clayton, A. \& Tabi, Z. Exosomes and the MICA-NKG2D system in cancer. Blood Cells Mol Dis. 2005;34: 206-13.

33. Wieckowski EU, Visus C, Szajnik M. et al. Tumor-Derived Microvesicles Promote Regulatory T Cell Expansion and Induce Apoptosis in Tumor-Reactive Activated CD8+ T Lymphocytes. J Immunol. 2009;183: 3720-3730.

34. Kim JW, Wieckowski E, Taylor DD. et al. Fas ligand-positive membranous vesicles isolated from sera of patients with oral cancer induce apoptosis of activated T lymphocytes. Clin Cancer Res. 2005;11: 1010-1020.

35. Cai Z, Yang F, Yu L. et al. Activated T Cell Exosomes Promote Tumor Invasion via Fas Signaling Pathway. J. Immunol. 2012;188: 5954-5961 (2012).

36. Kosaka N, Iguchi H, Hagiwara K. et al. Neutral sphingomyelinase 2 (nSMase2)-dependent exosomal transfer of angiogenic micrornas regulate cancer cell metastasis. J. Biol Chem. 2013;288: 10849-10859.

37. Al-Nedawi K, Meehan B, Kerbel RS, Allison AC \& Rak J. Endothelial expression of autocrine VEGF upon the uptake of tumor-derived microvesicles containing oncogenic EGFR. Proc Natl Acad Sci. 2009;106: 3794-3799 (2009).

38. Peinado H, Alečković M, Lavotshkin S. et al. Melanoma exosomes educate bone marrow progenitor cells toward a pro-metastatic phenotype through MET. Nat Med. 2012;18: 883-891.

39. Tominaga, N. et al. Brain metastatic cancer cells release microRNA-181c-containing extracellular vesicles capable of destructing blood-brain barrier. Nat Commun. 2015;6: 6716.

40. Sidhu SS, Mengistab AT, Tauscher AN., LaVail J \& Basbaum C. The microvesicle as a vehicle for EMMPRin in tumor-stromal interactions. Oncogene. 2004;23: 956-963.

41. Kosaka N, Iguchi H \& Ochiya T. Circulating microRNA in body fluid: A new potential biomarker for cancer diagnosis and prognosis. Cancer Sci. 2010;101: 2087-2092.

42. Kosaka N, Yoshioka Y, Fujita Y \& Ochiya T. Versatile roles of extracellular vesicles in cancer. J. Clin. Invest. 2016;126: 1163-1172.

43. Tominaga N, Yoshioka $Y$ \& Ochiya T. A novel platform for cancer therapy using extracellular vesicles. Adv Drug Deliv Rev 2015;95: 50-55.

44. Ohno SI, Drummen GPC \& Kuroda M. Focus on extracellular vesicles: Development of extracellular vesicle-based therapeutic systems. Int J Mol Sci. 2016;1.

45. Nishida-Aoki N, Tominaga N, Takeshita F, et al. Disruption of Circulating Extracellular Vesicles as a Novel Therapeutic Strategy against Cancer Metastasis. Mol Ther. 2017;25: 181-191.

46. Vader P, Breakefield XO \& Wood MJA. Extracellular vesicles: Emerging targets for cancer therapy. Trends Mol Med. 2014;20: 385-393.

47. Urbanelli L, Buratta S, Sagini K, Tancini B \& Emiliani C. Extracellular vesicles as new players in cellular senescence. Int J Mol Sci. 2016;17.

48. Raj DAA, Fiume I, Capasso G \& Pocsfalvi G. A multiplex quantitative proteomics strategy for protein biomarker studies in urinary exosomes. Kidney Int. 81, 1263-1272 (2012). 
49. Weilner S, Keider V, Winter M. et al. Vesicular Galectin-3 levels decrease with donor age and contribute to the reduced osteo-inductive potential of human plasma derived extracellular vesicles. Aging. 2016;8: 16-33.

50. Takasugi M, Okada R, Takahashi A. et al. Small extracellular vesicles secreted from senescent cells promote cancer cell proliferation through EphA2. Nat Commun. 2017;8: 15729.

51. Pienimaeki-Roemer A, Kuhlmann K, Böttcher A, et al. Lipidomic and proteomic characterization of platelet extracellular vesicle subfractions from senescent platelets. Transfusion. 2015;55: 507-521.

52. Mitsuhashi M, Taub DD, Kapogiannis D. et al. Aging enhances release of exosomal cytokine mRNAs by A1-42-stimulated macrophages. FASEB J. 2013;27: 5141-5150.

53. Weilner S, Schraml E, Wieser M. et al. Secreted microvesicular miR-31 inhibits osteogenic differentiation of mesenchymal stem cells. Aging Cel.I 2016;15: 744-754.

54. Davis, C. et al. MicroRNA-183-5p Increases with Age in Bone-Derived Extracellular Vesicles, Suppresses Bone Marrow Stromal (Stem) Cell Proliferation, and Induces Stem Cell Senescence. Tissue Eng Part A. 2017;0.

55. Wang Y, Fu B, Sun X. et al. Differentially expressed microRNAs in bone marrow mesenchymal stem cell-derived microvesicles in young and older rats and their effect on tumor growth factor- $\beta 1$ mediated epithelial-mesenchymal transition in HK2 cells. Stem Cell Res Ther. 2015;6: 1-11.

56. Machida T, Tomofuji T, Ekuni D, et al. MicroRNAs in salivary exosome as potential biomarkers of aging. Int J Mol Sci. 2015;16, 21294-21309.

57. Pienimaeki-Roemer A, Konovalova T, Musri MM, et al. Transcriptomic profiling of platelet senescence and platelet extracellular vesicles. Transfusion, 2017;57: 144-156.

58. Kangas R, Törmäkangas T, Fey V. et al. Aging and serum exomiR content in women-effects of estrogenic hormone replacement therapy. Sci. Rep. 7, 42702 (2017).

59. Takahashi A, Okada R, Nagao K, et al. Exosomes maintain cellular homeostasis by excreting harmful DNA from cells. Nat Commun. 2017;8, 15287 (2017).

60. da Silveira JC, Veeramachaneni DNR, Winger QA, Carnevale EM \& Bouma GJ. Cell-Secreted Vesicles in Equine Ovarian Follicular Fluid Contain miRNAs and Proteins: A Possible New Form of Cell Communication Within the Ovarian Follicle1. Biol Reprod. 2012;86: 1-10.

61. Simoncini S, Chateau AL Robert S, et al. Biogenesis of Pro-senescent Microparticles by Endothelial Colony Forming Cells from Premature Neonates is driven by SIRT1-Dependent Epigenetic Regulation of MKK6. Sci Rep. 2017;7: 8277.

62. Alberro A, Sáenz-Cuesta M, Muñoz-Culla M, et al. Inflammaging and frailty status do not result in an increased extracellular vesicle concentration in circulation. Int J Mol Sci. 2016;17: 1-7.

63. Eitan, E. et al. Age-Related Changes in Plasma Extracellular Vesicle Characteristics and Internalization by Leukocytes. Sci. Rep. 2017;7: 1342.

64. Saugstad JA, Lusardi TA, Van Keuren-Jensen KR, et al. Analysis of extracellular RNA in cerebrospinal fluid. J. Extracell. Vesicles 2017;6: 1317577.

65. Cazzoli R, Buttitta F, Di Nicola M, et al. microRNAs derived from circulating exosomes as noninvasive biomarkers for screening and diagnosing lung cancer. J Thorac Oncol. 2013;8: 1156-1162.

66. Katsuda T, Kosaka N, \& Ochiya T. The roles of extracellular vesicles in cancer biology: toward the development of novel cancer biomarkers. Proteomics. 2014;14: 412-425.

67. Wang AL, Lukas TJ, Yuan M,. et al. Autophagy and exosomes in the aged retinal pigment epithelium: possible relevance to drusen formation and age-related macular degeneration. PLoS One. 2009;4: e4160.

68. Wang AL, Lukas TJ, Yuan M, et al. Autophagy, exosomes and drusen formation in age-related macular degeneration. Autophagy. 2009;5: 563-564.

69. Eitan E, Zhang S, Witwer KW \& Mattson MP. Extracellular vesicle-depleted fetal bovine and human sera have reduced capacity to support cell growth. J. Extracell. vesicles 2015;4: 26373.

70. van Balkom BW, de Jong OG, Smits M, et al. Endothelial cells require miR-214 to secrete exosomes that suppress senescence and induce angiogenesis in human and mouse endothelial cells. Blood. 2013;121: 3997-4006.

71. Kadota T, Fujita Y, Yoshioka Y, et al. Emerging role of extracellular vesicles as a senescence- 
associated secretory phenotype: Insights into the pathophysiology of lung diseases. Mol Aspects Med. 2017. doi:10.1016/j.mam.2017.11.005

72. Bhowmick NA, Neilson EG \& Moses HL. Stromal fibroblasts in cancer initiation and progression. Nature. 2014;432: 332-337.

73. Reuter S, Gupta SC, Chaturvedi MM \& Aggarwal BB. Oxidative stress, inflammation, and cancer: How are they linked? Free Radic Biol Med. 2010;49: 1603-1616.

74. Guadagni, F. et al. Review. TNF/VEGF cross-talk in chronic inflammation-related cancer initiation and progression: an early target in anticancer therapeutic strategy. In Vivo. 2007;21: 147-161.

75. Karin, M. \& Greten, F. R. NF-kappaB: linking inflammation and immunity to cancer development and progression. Nat. Rev. Immunol. 2005;5: 749-759. 